\title{
Survival of mechanically ventilated patients admitted to intensive care units
}

\author{
Results from a tertiary care center between 2016-2018
}

Taha Ismaeil, MSc, PhD, Jawaher Almutairi, BSRT, Rema Alshaikh, BSRT, Zahrah Althobaiti, BSRT, Yassin Ismaiel, RRT-BSRT, MME, Fatmah Othman, MD, PhD.

\begin{abstract}
الأهداف: تقدير بقاء المرضى البالغين والأطفال الذين يتلقون تهوية

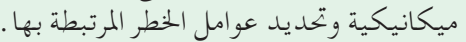

الطريقة: أجريت دراسة الأتراب بأثر رجعي في وحدة العناية المركزة (ICU )

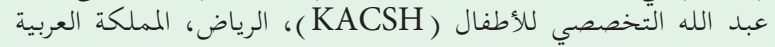

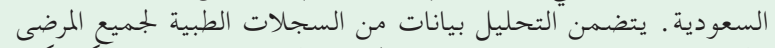

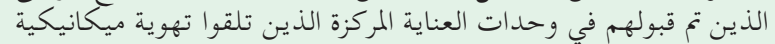

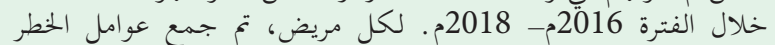

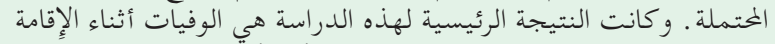
في وحدة العناية المركزة بعد تلقيجي التئيسية لهذهية الميكانيكيّة

النتائج : قبل 262 من البالغين و175 من مرضى الأطفال في وحسدات العناية

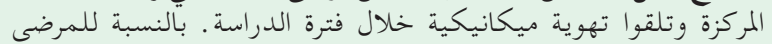

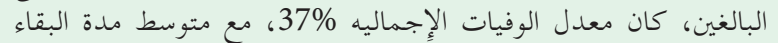

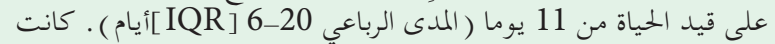

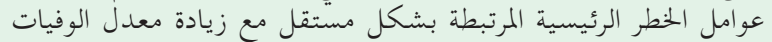

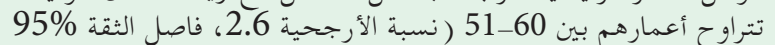

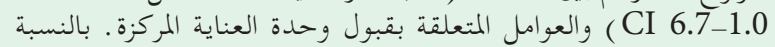

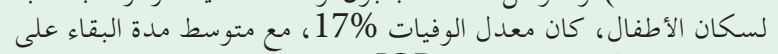

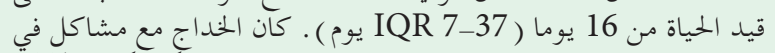

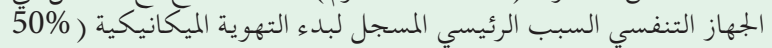

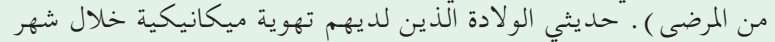

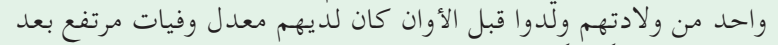
بلدء التهوية الميكانيكية.

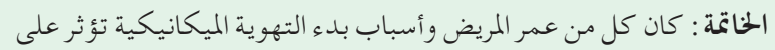

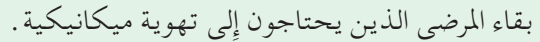

Objectives: To estimate the survival of adult and pediatric patients receiving mechanical ventilation and determine the associated risk factors

Methods: A retrospective cohort study was carried out in the intensive care unit (ICU) at King Abdulaziz Medical City (KAMC) and King Abdullah Children's Specialist Hospital (KACSH), Riyadh, Saudi Arabia. The analysis includes data from medical records of all patients admitted to ICUs who received mechanical ventilation between 2016-2018. For each patient, potential risk factors were collected. The main outcome of this study was the mortality during the stay in ICU after receiving mechanical ventilation

Results: A total of 262 adults and 175 pediatric patients were admitted to ICUs and received mechanical ventilation during the study period. For adult patients, the overall mortality was $37 \%$, with a median survival time of 11 days (interquartile range [IQR] 6-20 days). The main risk factors independently associated with the increased mortality rate were being aged 51-60 (odds ratio [OR] 2.6, 95\% confidence interval [CI] 6.7-1.0) and factors related to ICU admission. For the pediatric population, the mortality rate was $17 \%$, with a median survival time of 16 days (IQR 7-37 days). Prematurity with respiratory problems was the main recorded cause of initiation of mechanical ventilation ( $50 \%$ of patients). Neonates who had mechanical ventilation within one month of their birth and were born extremely preterm had a high mortality rate after the initiation of mechanical ventilation.

Conclusion: Both patient age and the causes of the initiation of mechanical ventilation were influencing the survival of patients who required mechanical ventilation.

\section{Saudi Med J 2019; Vol. 40 (8): 781-788} doi: 10.15537/smj.2019.8.24447

From the Department of Respiratory Therapy (Ismaeil, Almutairi, Alshaikh, Althobaiti, Ismaiel), from the Research Unit (Othman), College of Applied Medical Sciences, King Saud bin Abdulaziz University for Heath Sciences, and King Abdullah International Medical Research Center (Ismaeil, Othman), Riyadh, Kingdom of Saudi Arabia.

Received 2nd April 2019. Accepted 28th July 2019.

Address correspondence and reprint request to: Dr. Fatmah Othman, Research Unit, College of Applied Medical Sciences, King Saud bin Abdulaziz University for Heath Sciences, Riyadh, Kingdom of Saudi Arabia.E-mail: othmanf@ksau-hs.edu.sa ORCID ID: 0000-0002-6846-4632 
M echanical ventilation is considered an important aspect of the supportive management of patients in intensive care units (ICUs). Many studies have reported an increased rate of using mechanical ventilation over the last 7 years. This increase is attributable to increases in demand for acute and critical care delivery in many health care systems. This demand is being caused by an increasingly aging population, an increase in the survival of patients with comorbidity and cancer, an increase in the number of ICU beds, and the advancements in therapy management. ${ }^{1-3}$ Thus, many observational studies have examined the use of mechanical ventilation and its associated outcomes, some of which have focused on estimating the mortality rate and identifying the factors related to the survival of patients who received mechanical ventilation. ${ }^{4-7}$

Data on the survival of patients admitted to ICUs and requiring mechanical ventilation, therefore, are varied. The variability in survival data reflects differences in ICU patients' selection criteria, patient care standards, and the characteristics of the population. In 2002, Esteban et $\mathrm{al}^{8}$ evaluated the outcomes of adult patients admitted to ICUs and showed that the overall mortality rate was $52 \%$ among patients receiving mechanical ventilation. Another study by the same research group showed that crude mortality rate in ICUs had been decreased in 2010 compared to that in 1998 (31\% versus 28\%). ${ }^{9}$ This improvement was related to the improvement in clinical practices over the period. Additionally, studies have reported that many factors related to the initiation of mechanical ventilation as well as other factors related to the management plan and complication during the course of mechanical ventilation affect the survival of patients receiving mechanical ventilation. ${ }^{8,10}$

In Saudi Arabia, many studies have examined the mortality outcome of patients admitted to ICUs; however, some of those studies have evaluated the outcome of patients receiving mechanical ventilation for specific indications, such as with severe respiratory conditions, ${ }^{11,12}$ or have focused on a specific population such as that with a hematological malignancy. ${ }^{11-14}$ However, the survival of patients admitted to an ICU and received mechanical ventilation with various indications and among heterogenous population has not been reported in Saudi Arabia. The aim of this study; therefore, was to estimate the survival of adult

Disclosure. Authors have no conflict of interests, and the work was not supported or funded by any drug company. and pediatric patients admitted to ICU and received mechanical ventilation, and to determine the associated factors influencing the survival. The results of this study will help in identifying patients at risk and planning appropriate preventive measures.

Methods. A retrospective cohort study was conducted between February 2016 and February 2018 in the medical-surgical intensive care department at King Abdulaziz Medical City (KAMC) and King Abdullah Children's Specialist Hospital (KACSH), Riyadh. The Intensive Care Department has a 62-bed capacity KACSH. ${ }^{15,16}$ Data were collected consecutively from all intubated patients (pediatric and adult) who had been admitted to the ICU and required mechanical ventilation for more than 24 consecutive hours during the study period; therefore, we included all eligible patients in this study who met the study inclusion criteria. We excluded patients who received non-invasive ventilation, and those who died within 24 hours of receiving the mechanical ventilation.

The main outcome of this study was all the causes of mortality during the stay in ICUs after receiving mechanical ventilation. The mortality rate was calculated as all mechanically ventilated patients who died in ICUs during the study period over the total number of mechanically ventilated patients in ICUs during the same year. Also, we estimated the length of stay in ICUs for those patients as we collected information on time and date of receiving mechanical ventilation, time and date of death, and time and date of ICU discharge. Moreover, for the adult population, the following information was collected from each patient's medical file on the day of ICU admission: 1) demographic variables, body mass index (BMI) (categorized into underweight, normal, overweight, and obese); 2) source of ICU admission (from emergency department, other that includes hospital ward, transfer from other hospital, or outpatient department); 3) Glasgow coma scale that (classified into severe brain injury, score 1-8; moderate brain injury, score 9-12, and mild brain injury, score 13-15); 4) mechanical ventilator setting; 5) cause of the initiation of mechanical ventilation (classified into coma, respiratory failure type I, respiratory failure type II, and other causes such as involved in motor vehicle accidents, burns, or post-operative complications); and 6) diagnosis at ICU admission (mapped on the ICD-10 classification of disease). For pediatric patients, we also extracted information on the demographics (in which we classified the age into first month, 2-12 months, and more than 12 months), source of ICU admission (from ER, labor suite, or other hospital), gestational 
week (classified according to the WHO classification of prematurity), cause of the initiation of mechanical ventilation (classified into prematurity with respiratory problems, respiratory distress syndrome, post-operation, and congenital), and diagnosis at ICU admission (mapped on the ICD-10 classification of disease).

Baseline characteristics of patients at the time of ICU admission were reported as number and percentage for categorical variables and as mean and standard deviation (SD) for normally distributed continuous variables, or as the median and interquartile range (IQR) if not. The primary outcome measure was the mortality during the ICU stay after the initiation of mechanical ventilation. A Kaplan-Meier curve was used to describe the probability of survival after the initiation of mechanical ventilation; thus the exit time was set as the earliest of either the death date or the ICU discharge date. To examine the association effect of the factors on the survival among those who survived and those who died, a univariate analysis was performed using logistic regression to estimate the odds ratio (OR) and $95 \%$ confidence interval (95\% CI), whereby $p<0.05$ was considered as significant. The statistical analyses were performed using $\mathrm{STATA}^{\odot}$ software, version 15 (StataCorp, College Station, TX, USA).

The study was approved by the research ethics committee of King Abdullah International Medical Research Center, Riyadh, Saudi Arabia protocol number (SP18/168/R).

Results. Overall, among the 437 patients (all populations), 128 patients died after receiving mechanical ventilation. Thus, the overall mortality for patients admitted to the ICU and receiving mechanical ventilation during the study period was $29 \%$, with a median survival time of 12 days (IQR 6-25 days). Kaplan-Meier curve (Figure 1) compared the survival rates between the adult and pediatric populations in which the $P$ value from the log rank test was $(p<0.05)$ which indicates a significant difference between the population survival curves. We reported the results for the adult and pediatric populations separately as the cause of the initiation of mechanical ventilation and the type of mechanical ventilation mode are different between the adult and pediatric populations.

In the analysis of adult population, a total of 262 patients were admitted to ICUs and received mechanical ventilation during the study period. The mean age of those patients was 57 (SD 21) years, and the majority were male (64\%). Of 262 patients, 98 patients died after receiving mechanical ventilation. Thus, the overall mortality for patients admitted to ICUs and receiving mechanical ventilation during the study period was $37 \%$, with a median survival time in the ICU of 11 days (IQR 6-20 days). Because the average duration of mechanical ventilation was 11 days, the analysis was restricted to within 30 days of receiving mechanical ventilation. The mortality rate was 27.3 per 1000 -person years (95\% CI 22.4 to 33.2). The Kaplan-Meier survival curves for 30-day ICU mortality is shown in Figure 2. At the end of 30 days after receiving the mechanical ventilation, the overall survival rate was $82 \%$ after the fifth day and $75 \%$ after the tenth day of receiving the mechanical ventilation.

The main indication of mechanical ventilation among those patients was respiratory failure type I (124 patients, $47.3 \%)$ followed by a coma $(24.1 \%)$ as summarized in Table 1. Although most of the patients had multiple diagnoses for their ICU admission, circulatory disease was the second most common primary diagnosis for this (18\%), followed by respiratory disease (12.9\%). A total of 195 (74.4\%) of the patients were intubated in the ICU while $25.5 \%$ had already been intubated before

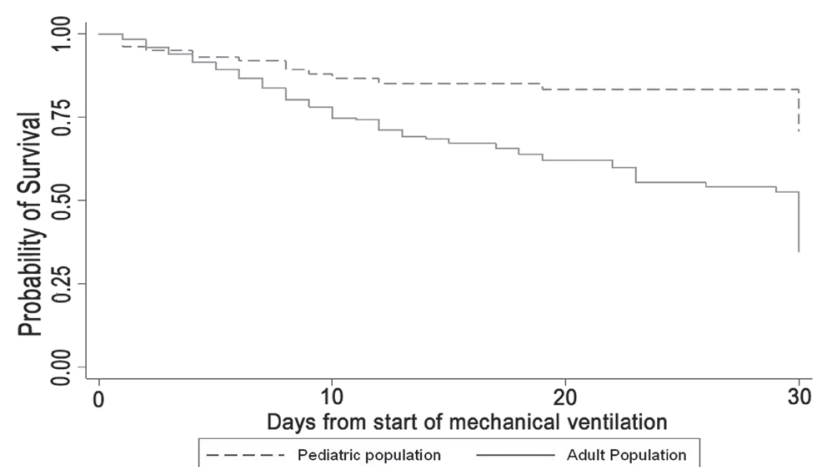

Figure 1 - Kaplan-Meier curves of the probability of survival over time for all mechanical ventilated patients (adult and pediatric) admitted to the intensive care unit.

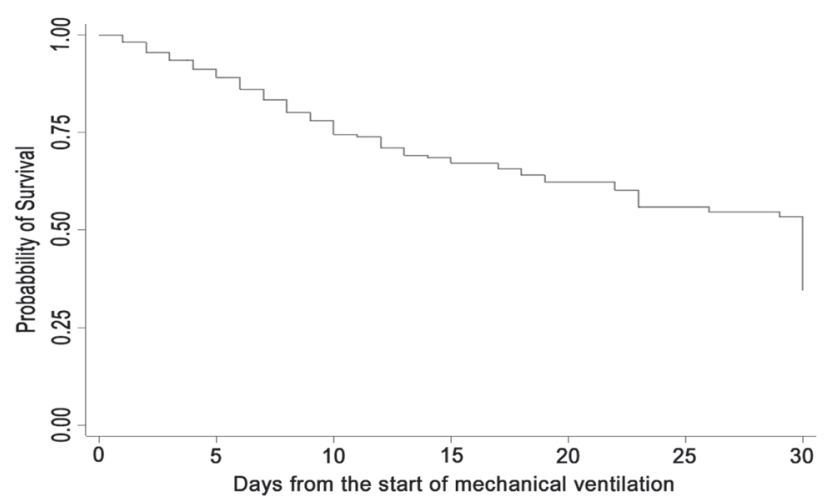

Figure 2 - Kaplan-Meier curves of the probability of survival over time for adult mechanical ventilated patients $(\mathrm{N}=262)$ admitted to the intensive care unit between 2016-2018. 
Table 1 - Demographic, clinical characteristics, and initial ventilator modes of the adult patients on the inanition of the mechanical ventilation in the intensive care unit between 2016-2018 ( $\mathrm{N}=262)$.

\begin{tabular}{|c|c|c|}
\hline \multirow{2}{*}{$\begin{array}{l}\text { Patients characteristic } \\
\text { Age category(years) }\end{array}$} & \multicolumn{2}{|c|}{$\begin{array}{c}\text { Patients mechanically } \\
\text { ventilated }\end{array}$} \\
\hline & & \\
\hline \\
\hline $31-40$ & \multicolumn{2}{|l|}{$24(9.2)$} \\
\hline $41-50$ & \multicolumn{2}{|l|}{$19(7.2)$} \\
\hline $51-60$ & \multicolumn{2}{|l|}{33 (12.6) } \\
\hline $61-70$ & \multicolumn{2}{|l|}{$42(16.0)$} \\
\hline$\geq 71$ & \multicolumn{2}{|l|}{$95(36.3)$} \\
\hline \multicolumn{3}{|l|}{ Gender } \\
\hline Female & \multicolumn{2}{|l|}{$93(35.5)$} \\
\hline \multicolumn{3}{|l|}{ Body mass index } \\
\hline Underweight & \multicolumn{2}{|l|}{$20(7.6)$} \\
\hline Normal & \multicolumn{2}{|l|}{$94(35.8)$} \\
\hline Overweight & \multicolumn{2}{|l|}{$72(27.4)$} \\
\hline Obese & \multicolumn{2}{|l|}{$79(29.0)$} \\
\hline \multicolumn{3}{|l|}{ Glasgow coma scale } \\
\hline Severe brain injury & \multicolumn{2}{|l|}{$216(90.3)$} \\
\hline Moderate brain injury & $15(6.3)$ & \\
\hline Mild brain injury & $8(3.3)$ & \\
\hline $\begin{array}{l}\text { Cause of initiation of mechanical } \\
\text { ventilation }\end{array}$ & & \\
\hline Coma & $63(24.1)$ & \\
\hline Respiratory failure type I & $124(47.3)$ & \\
\hline Respiratory failure type II & $27(10.3)$ & \\
\hline Other causes & $27(10.3)$ & \\
\hline Diagnosis at ICU admission & & \\
\hline Diseases of the respiratory system & $34(12.9)$ & \\
\hline Diseases of the circulatory system & $49(18.7)$ & \\
\hline Diseases of the nervous system & $18(6.8)$ & \\
\hline Certain infectious and parasitic diseases & $25(9.5)$ & \\
\hline $\begin{array}{l}\text { Injury, poisoning and certain other } \\
\text { consequences of external causes }\end{array}$ & $39(14.8)$ & \\
\hline Neoplasms & $4(1.5)$ & \\
\hline Diseases of the digestive system & $11(4.2)$ & \\
\hline Diseases of the genitourinary system & $3(1.1)$ & \\
\hline $\begin{array}{l}\text { Diseases of the musculoskeletal system and } \\
\text { connective tissue }\end{array}$ & $1(0.4)$ & \\
\hline Multiple causes & $78(29.7)$ & \\
\hline Place of intubation (\%) & & \\
\hline in ICU & $195(74.4)$ & \\
\hline out ICU & $67(25.5)$ & \\
\hline Ventilator mode (\%) & & \\
\hline АСРC & $1(0.8)$ & \\
\hline ACVC & $6(2.3)$ & \\
\hline PRVC & $18(6.8)$ & \\
\hline PSV & $1(0.3)$ & \\
\hline $\mathrm{VC}$ & $236(90.1)$ & \\
\hline $\begin{array}{l}\text { Ventilator parameter Mean }\left(S D^{*}\right) /\{\text { median } \\
\left.\left(I Q R^{* *}\right)\right\}\end{array}$ & & \\
\hline The fraction of inspired oxygen (Fio2) & $76(24.0)$ & $80(30-60)$ \\
\hline Respiratory rate, breaths/min & $21.1(3.7)$ & $20(18-23)$ \\
\hline Tidal volume, $\mathrm{ml}$ & $392.7(50.3)$ & $400(370-400)$ \\
\hline Peak inspiratory pressure & $23.9(6.4)$ & $24(19-28)$ \\
\hline Mean airway pressure & $12.1(3.7)$ & $11(9.5-14)$ \\
\hline Positive end expiratory pressure, $\mathrm{cmH} 2 \mathrm{O}$ & $6.6(2.6)$ & $5(5-6)$ \\
\hline Lab results Mean $(S D) /$ median $(I Q R)$ & & \\
\hline WBC count $\times 10^{\wedge} 9 / \mathrm{L}$ & $23.3(147.9)$ & $13.4(8.4-19)$ \\
\hline Hematocrit L/L & $2.1(19.5)$ & $0.37(0.3-0.4)$ \\
\hline Creatinine umol/L & $148.1(153.1)$ & $88(67-156)$ \\
\hline Sodium $\mathrm{mmol} / \mathrm{L}$ & $138.8(6.1)$ & $139(135-141)$ \\
\hline Potassium $\mathrm{mmol} / \mathrm{L}$ & $3.9(0.8)$ & $3.8(3.1-4.4)$ \\
\hline Mean arterial pressure & $87.4(23.2)$ & \\
\hline$p H$ & $7.3(0.1)$ & \\
\hline $\begin{array}{l}\text { Values are presented as numbers and percent } \\
\text { interval. SD - standard deviation, ICU - inte } \\
\text { range, ACPC - assist-control/pressure contr } \\
\text { control, PRVC - pressure-regulated volume } \\
\text { ventilation, VC - volu }\end{array}$ & $\begin{array}{l}(\%) .{ }^{*} 95 \% \text { CI: } \\
\text { ve care unit, IQR } \\
\text { ACVC - assist-cc } \\
\text { ntrol, PSV - pres } \\
\text { control }\end{array}$ & $\begin{array}{l}5 \% \text { confidence } \\
\text { interquartile } \\
\text { trrol/volume } \\
\text { ure support }\end{array}$ \\
\hline
\end{tabular}

ICU admission. Among those who were intubated in the ICU, the majority were intubated within the first 24 hours of ICU admission. The table indicates that the patients whose mechanical ventilation was initiated due to other causes had a significantly lower risk of death compared to those in a coma or with respiratory failure The ventilator settings and parameters and monitored variables on day one of mechanical ventilation are presented in (Table 1).

In relation to the clinical and morbidity variables, the results of the univariate analysis of factors associated with the mortality of ventilated patients in ICUs (Table 2). Among the factors we collected in this study and included in the univariate analysis, the following were found to be associated with the mortality among mechanically ventilated adult patients: being aged 51-60 (OR 2.6, 95\% CI 1.05-6.7); admission to ICUs with diseases of the circulatory system (OR 3.14, 95\% CI 1.21-8.1); and admission to ICUs with certain infectious or parasitic diseases (OR 11.1, 95\% CI 3.21-38.4).

In this analysis, a total of 175 patients were admitted to ICUs and received mechanical ventilation during the study period. Most of the patients were below 1 month ( $89 \%$ of the whole population) and $59 \%$ were boys. A total of $30(17 \%)$ of this study population died after the date of mechanical ventilation with a median survival time of 16 days (IQR 7-37 days). The mortality rate was 9.9 per 1000 -person years ( $95 \%$, CI 6.96 to 14.25 ). The Kaplan-Meier survival curves for 30-day ICU mortality as shown in Figure 3. The curve shows that by the end of one month, $75 \%$ of patients on mechanical ventilation are still alive. The characteristic of the population as demonstrated in Table 3. The main source of the admission of those neonates was labor and delivery by C-section, with the mean gestational week being 32 (SD 5) weeks. Prematurity with respiratory problems

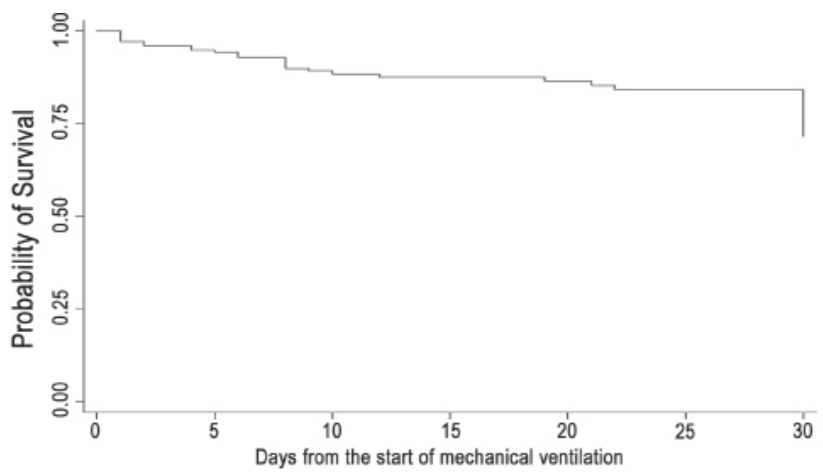

Figure 3 - Kaplan-Meier curves of the probability of survival overtime for pediatric mechanical ventilated patients $(\mathrm{N}=175)$ admitted to the intensive care unit between 2016-2108. 
Table 2 - The univariate analysis of factors associated with mortality among adult patients who admitted to ICU and received mechanical ventilation between 2016-2018.

\begin{tabular}{|c|c|c|c|c|}
\hline \multirow{2}{*}{$\begin{array}{l}\text { Independent variable } \\
\text { Age category (years) }\end{array}$} & \multirow[t]{2}{*}{$\begin{array}{c}\text { Mechanically } \\
\text { ventilated patient } \\
\text { who survive }\end{array}$} & \multirow[t]{2}{*}{$\begin{array}{c}\text { Mechanically } \\
\text { ventilated patients } \\
\text { who die }\end{array}$} & \multicolumn{2}{|c|}{ Odds ratio $(95 \% \mathrm{CI})^{*}$} \\
\hline & & & & \\
\hline $18-30$ & $35(21)$ & $14(14)$ & 1.0 & \\
\hline $31-40$ & $20(12)$ & $4(4)$ & 0.5 & $(0.14-1.72)$ \\
\hline $41-50$ & $12(7)$ & $7(7)$ & 1.45 & $(0.47-4.46)$ \\
\hline $51-60$ & $16(10)$ & $17(17)$ & 2.65 & $(1.05-6.70)$ \\
\hline $61-70$ & $27(16)$ & $15(15)$ & 1.38 & $(0.57-3.36)$ \\
\hline$\geq 71$ & $54(32)$ & $41(41)$ & 1.89 & $(0.90-3.98)$ \\
\hline \multicolumn{5}{|l|}{ Gender } \\
\hline Female & $20(12)$ & $4(4)$ & 0.5 & $(0.14-1.72)$ \\
\hline \multicolumn{5}{|l|}{ Body mass index } \\
\hline Underweight & $14(8)$ & $6(6)$ & 1.0 & \\
\hline Normal & $61(37)$ & $33(33)$ & 1.26 & $(0.44-3.59)$ \\
\hline Overweight & $46(28)$ & $26(26)$ & 1.32 & $(0.45-3.84)$ \\
\hline Obese & $43(26)$ & $33(33)$ & 1.78 & $(0.62-5.16)$ \\
\hline \multicolumn{5}{|l|}{ Glasgow coma scale } \\
\hline Severe brain injury & $134(90)$ & $82(90)$ & 1 & \\
\hline Moderate brain injury & $8(5)$ & $7(7)$ & 1.42 & $(0.49-4.08)$ \\
\hline Mild brain injury & $6(4)$ & $2(2)$ & 0.54 & $(0.10-2.76)$ \\
\hline Cause of initiation of mechanical ventilation & $23(14)$ & $4(4)$ & 0.23 & $23(14)$ \\
\hline Coma & $36(21)$ & $27(27)$ & 1 & \\
\hline Respiratory failure type I & $71(43)$ & $53(54)$ & 0.99 & $(0.53-1.83)$ \\
\hline Respiratory failure type II & $34(20)$ & $14(14)$ & 0.54 & $(0.24-1.21)$ \\
\hline Other causes & $23(14)$ & $4(4)$ & 0.23 & $(0.07-0.74)$ \\
\hline Diagnosis at ICU admission & $5(3)$ & $20(20)$ & 11.1 & $5(3)$ \\
\hline Diseases of the respiratory system & $25(15)$ & $9(9)$ & 1 & \\
\hline Diseases of the circulatory system & $23(14)$ & $26(26)$ & 3.14 & $(1.21-8.09)$ \\
\hline Diseases of the nervous system & $15(9)$ & $3(3)$ & 0.55 & $(0.12-2.38)$ \\
\hline Certain infectious and parasitic diseases & $5(3)$ & $20(20)$ & 11.1 & $(3.21-38.44)$ \\
\hline Injury, poisoning and certain other consequences of external causes & $27(16)$ & $12(12)$ & 1.23 & $(0.44-3.42)$ \\
\hline Neoplasms & $2(1)$ & $2(2)$ & 2.77 & $(0.33-22.64)$ \\
\hline Diseases of the digestive system & $6(3)$ & $5(5)$ & 2.31 & $(0.56-9.48)$ \\
\hline Diseases of the genitourinary system & $2(1)$ & $1(1)$ & 1.38 & $(0.11-17.23)$ \\
\hline Diseases of the musculoskeletal system and connective tissue & $1(0.6)$ & $0(0)$ & - & - \\
\hline Multiple causes & $58(35)$ & $20(41)$ & 0.95 & $(0.38-2.39)$ \\
\hline
\end{tabular}

$(50 \%)$ was the main recorded cause of the initiation of mechanical ventilation, followed by respiratory distress syndrome (37\%). The majority of admissions to ICUs were premature. Neonates who received mechanical ventilation within the first month of their life and who were born extremely preterm had a high mortality rate after the initiation of mechanical ventilation. A total of $169(96 \%)$ of the neonates were intubated in ICU while only 3\% had already been intubated before their ICU admission. Variables related to mechanical ventilation parameters on day one of mechanical ventilation are presented in Table 3. For the results of the univariate analysis of factors associated with mortality among this population, Table 4 shows that neonates who received mechanical ventilation within the first month of life and who were born extremely preterm had a high mortality rate after the initiation of mechanical ventilation. In addition, those neonates who had respiratory distress syndrome as the cause of initiating the mechanical ventilation had a high rate of mortality; however, the univariate analysis showed no significant association. Neonates who had congenital anomalies as the cause of receiving mechanical ventilation were more likely to have a lower survival rate (OR 13, 95\% CI 2.68-62.8).

Discussion. The results of this study showed that the mortality rate of adult patients who required mechanical ventilation was $37 \%$ and that of the pediatric population was $17 \%$. Elderly patients and those with circulatory system disease and infection as admission cause to ICU have higher mortality rate after 
Table 3 - Demographic, clinical characteristics, and initial ventilator modes of the pediatric patients on the inanition of the mechanical ventilation in the ICU between 2016-2018 $(\mathrm{N}=175)$.

\begin{tabular}{|c|c|c|}
\hline \multirow{2}{*}{$\begin{array}{l}\text { Patients characteristic } \\
\text { Age category (months) }\end{array}$} & \multicolumn{2}{|c|}{ Patients mechanically ventilated } \\
\hline & & \\
\hline First month & $157(89.0)$ & \\
\hline 2-12 month & $9(5.1)$ & \\
\hline$>12$ month & $9(5.1)$ & \\
\hline \multicolumn{3}{|l|}{ Gender } \\
\hline Female & $71(41.0)$ & \\
\hline \multicolumn{3}{|l|}{ Gestational week } \\
\hline Extremely preterm & $43(24.6)$ & \\
\hline Very preterm & $57(32.6)$ & \\
\hline Moderate to late preterm & $32(18.3)$ & \\
\hline Full term & $43(24.6)$ & \\
\hline \multicolumn{3}{|l|}{ Cause mechanical ventilators } \\
\hline $\begin{array}{l}\text { prematurity with respiratory } \\
\text { problems }\end{array}$ & $88(50.3)$ & \\
\hline Respiratory distress syndrome & $65(37.1)$ & \\
\hline Post-operation & $14(8)$ & \\
\hline congenital & $8(4.6)$ & \\
\hline \multicolumn{3}{|l|}{ Diagnosis } \\
\hline Prenatal disorder & $132(75.4)$ & \\
\hline congenital & $31(17.7)$ & \\
\hline combined & $12(6.9)$ & \\
\hline \multicolumn{3}{|l|}{ Place of intubation } \\
\hline in ICU & $169(96.57)$ & \\
\hline out ICU & $6(3.43)$ & \\
\hline \multicolumn{3}{|l|}{$\begin{array}{l}\text { Ventilator parameter Mean } \\
\left(S D^{*}\right) /\left\{\text { median }\left(I Q R^{\dagger}\right)\right\}\end{array}$} \\
\hline $\begin{array}{l}\text { The fraction of inspired } \\
\text { oxygen (Fio2) }\end{array}$ & $51.4(52.5)$ & $60(30-60)$ \\
\hline Respiratory rate, breaths/min & $51.5(11.2)$ & $40(30-60)$ \\
\hline Tidal volume, $\mathrm{ml}$ & $19.01(51.2)$ & $9.1(4.4-13)$ \\
\hline Peak inspiratory pressure, $\mathrm{cmH} 2 \mathrm{O}$ & $18.4(3.9)$ & $20(16-20)$ \\
\hline Mean airway pressure, $\mathrm{cmH} 2 \mathrm{O}$ & $9.8(1.7)$ & $10(8.7-11)$ \\
\hline MVe & $1.09(2.2)$ & $0.5(0.3-0.9)$ \\
\hline $\begin{array}{l}\text { Positive end expiratory } \\
\text { pressure, } \mathrm{cmH} 2 \mathrm{O}\end{array}$ & $5.9(0.6)$ & $6(6-6)$ \\
\hline \multicolumn{3}{|l|}{ Lab results } \\
\hline WBC count $x 10^{\wedge} 9 / \mathrm{L}$ & $11.42(6.1)$ & $10(7-14)$ \\
\hline Hematocrit L/L & $0.46(0.1)$ & $0.3(0.3-0.5)$ \\
\hline Creatinine umol/L & $60.5(42.8)$ & $56(49-65)$ \\
\hline Sodium mmol/L & $137.27(5.3)$ & $137(134-139)$ \\
\hline Potassium mmol/L & $7.05(37.8)$ & $4.1(3.6-4.7)$ \\
\hline$p H$ & $7.28(0.1)$ & \\
\hline \multicolumn{3}{|l|}{ Vital signs } \\
\hline Temperature C & $36.5(0.7)$ & \\
\hline Mean arterial pressure & $44.6(17.4)$ & \\
\hline Heart rate & $148.2(22.9)$ & \\
\hline $\begin{array}{l}\text { Values are presented as numbers an } \\
\text { interquartile range, ICU - intensive } \\
\text { Mve - exhaled min }\end{array}$ & $\begin{array}{l}\text { ercentage (\%). * } \\
\text { re unit, WBC - v } \\
\text { ventilation, } \mathrm{L} / \mathrm{m}\end{array}$ & $\begin{array}{l}\text { ndard deviation, } \\
\text { ite blood cells, }\end{array}$ \\
\hline
\end{tabular}

the initiation of mechanical ventilation. Similarly, the gestational age and cause of intubation were associated with a higher mortality rate among neonates.

Many studies in the literature have addressed mortality as an outcome among patients receiving mechanical ventilation. ${ }^{11,17-20}$ These studies provide valuable information on the epidemiology of mechanical ventilation and address the outcome of patients receiving mechanical ventilation. ${ }^{8,9}$ The finding of this study pertaining to the mortality rate among the adult population is consistent with the findings from earlier studies. ${ }^{8}$ Previous studies carried out in developed countries have shown an overall mortality rate of $30-44 \%$ among their population, while this reaches $70 \%$ in countries with a low-resource setting. ${ }^{8,21}$ A prospective cohort study including 15,757 patients estimated that the all-cause mortality was $52 \%$ in patients who received mechanical ventilation because of ARDS, while this was $22 \%$ in patients with COPD. ${ }^{8}$ The authors of that study estimated $40 \%$ as the mortality of patients receiving mechanical ventilation, while in our study we report $37 \%$ as the overall mortality. On the other hand, multicenter international studies have reported that short-term mortality has decreased among mechanically ventilated patients over time. ${ }^{9}$ However, the finding in this study concerning mortality in adult patients was higher than in another study that examined the trend of using mechanical ventilation over 10 years, from 1998 to 2010 , during which the mortality rate declined by $28 \%{ }^{9}$

Thus, in the published research, many studies have reported that age is an independent factor associated with mortality. ${ }^{8}$ Those studies have shown an effect of age on the mortality of patients who received mechanical ventilation, whereby they reported that age has an independent effect on the outcomes of those patients. Our data showed a higher percentage of patients who died after the initiation of mechanical ventilation in the 3 age categories 51-60, 61-70, and more than 71 years old. Also, the results of this study showed that the percentage of patients who were overweight was higher compared to the percentage of patients who died after the initiation of mechanical ventilation in the same category. This finding supports the concept of the obesity paradox, whereby many studies have indicated that obesity and morbid obesity are associated with a lower mortality rate in patients with ARDS. ${ }^{22}$ However, this was not significant in the univariate analysis

In addition, we were able to examine mortality among the pediatric population. Therefore, extreme prematurity was associated with a low survival rate, which is consistent with previous studies that examined the outcome of prematurity. ${ }^{23,24}$ As reported in many studies, ${ }^{23,24}$ we found that a higher percentage of patients who received mechanical ventilation were male; however, they were similar to females in terms of 
Table 4 - The univariate analysis of factors associated with mortality among adult patients who admitted to ICU and received mechanical ventilation between 2016-2018.

\begin{tabular}{|c|c|c|c|c|}
\hline Characteristics & $\begin{array}{l}\text { Mechanically ventilated } \\
\text { patient who survive }\end{array}$ & $\begin{array}{l}\text { Mechanically ventilated } \\
\text { patients who die }\end{array}$ & Odds ratio & $95 \% \mathrm{CI}^{*}$ \\
\hline \multicolumn{5}{|l|}{ Age category (months) } \\
\hline First month & $129(88)$ & $28(93)$ & 1.0 & \\
\hline 2-12 month & $7(5)$ & $2(6)$ & 1.32 & $0.25-6.67$ \\
\hline$>12$ month & $9(6)$ & 0 & - & - \\
\hline \multicolumn{5}{|l|}{ Gender } \\
\hline Female (\%) & $58(40)$ & $13(43)$ & 1.14 & $0.51-2.53$ \\
\hline \multicolumn{5}{|l|}{ Gestational week } \\
\hline Extremely preterm & $33(22)$ & $10(33)$ & 1.0 & \\
\hline Very preterm & $52(35)$ & $5(16)$ & 0.31 & $0.09-1.01$ \\
\hline Moderate to late preterm & $27(18)$ & $5(16)$ & 0.61 & $0.18-2.00$ \\
\hline Full term & $33(22)$ & $10(33)$ & 1.0 & $0.36-2.70$ \\
\hline \multicolumn{5}{|l|}{ Cause mechanical ventilators } \\
\hline Prematurity with respiratory problems & $78(53)$ & $10(33)$ & 1.0 & \\
\hline Respiratory distress syndrome & $50(34)$ & $15(50)$ & 2.34 & $0.97-5.61$ \\
\hline Post-operation & $14(10)$ & 0 & - & - \\
\hline Congenital & $3(2)$ & $5(16)$ & 13 & $2.68-62.83$ \\
\hline \multicolumn{5}{|l|}{ Diagnosis } \\
\hline Prenatal disorder & $112(77)$ & $20(66)$ & 1.0 & \\
\hline Congenital & $24(16)$ & $7(23)$ & 1.63 & $0.62-4.29$ \\
\hline Combined & $9(6)$ & $3(10)$ & 1.9 & $0.46-7.49$ \\
\hline
\end{tabular}

survival after the mechanical ventilation was initiated. Additionally, in the current study the majority of the pediatric population was within one month of age, thus this population is different from classic pediatric patients and this finding limits our generalizability of the results to the wider pediatric population.

The published prospective studies examining the mortality of mechanically ventilated patients described the mortality and evaluated the effect of many comorbidity variables that potentially related to mortality. They found that the survival of ICU patients depends on factors that develop during the course of the ventilation in addition to those factors that cause the initiation of mechanical ventilation. Although this point is considered a limitation in the current study, as we did not collect such information, the main aim of this study was to estimate the survival of a heterogeneous group of patients who were admitted to the ICU and required mechanical ventilation at one center in Saudi Arabia. Thus at a national level, many studies have been carried out that estimated mortality as one of many outcomes of patients admitted to ICUs. ${ }^{11}$ Thus, a limited number of studies has addressed this issue among patients with certain conditions such as malignancy or acute renal failure. ${ }^{13,25}$ An important consideration in our study was the outbreak of the Middle East Respiratory Syndrome Coronavirus (MERS-CoV) infection that occurred during the study period. Thus, MERS-CoV infection requiring admission to ICUs was associated with high mortality, as $72 \%$ such patients died in ICUs. ${ }^{12}$

The strengths of this study were, first, that the data were extracted from electronic records rather than handwritten to minimize errors in measurement; and second, that it addresses the mortality rate among both adult and pediatric ventilated patients without specifying conditions. Both KAMC and KACSH assign ICD-10 diagnosis codes for ICU admission diagnosis, whereby we adopt the same categories in the classification of the reason for ICU admission. Although this may be complex, re-grouping the principal diagnoses of ICU admission into mutually exclusive categories would impose further challenges as we may under- or overestimate the association of specific categories with others. On the other hand, one of the limitations of the study is related to the information concerning the severity of the patients: the APACHE II score, chronic use of corticosteroids, failure previous to mechanical ventilation, and other conditions occurring during mechanical ventilation were not studied. This study was observational in nature and the effect of many factors as well as unmeasured confounders cannot be fully controlled. However, we acknowledge that the presence of such information would be useful to give the full picture of our study population. Thus, based on previous studies, the severity of the disease and co-existing comorbidity are predictor factors associated with higher mortality among ICU patients. The small sample size in this study is considered one of the 
limitations of our analysis. Nevertheless, our purpose was to assess the overall mortality among mechanically ventilated patients who were admitted to the ICU in one center. A further retrospective multicenter study with appropriate statistical power and study design to include further confounders is essential to provide more realistic survival data on ICU patients in Saudi Arabia.

In conclusion, both patient age and the causes of the initiation of mechanical ventilation were influencing the survival of patients who required mechanical ventilation. Future studies should be planned to address the associated risk factor through integrating appropriate statistical approaches that encounter severity of the disease and co-existing comorbidity are predictor factors with mortality among ICU patients. For the meanwhile, efforts should be carefully planned when mechanical ventilation is needed among ICU patients.

\section{References}

1. Herring AA, Ginde AA, Fahimi J, Alter HJ, Maselli JH, Espinola JA, et al. Increasing critical care admissions from u.s. emergency departments, 2001-2009. Crit Care Med 2013; 41: 1197-1204.

2. Wunsch H, Wagner J, Herlim M, Chong DH, Kramer AA, Halpern SD. ICU occupancy and mechanical ventilator use in the United States. Crit Care Med 2013; 41: 2712-2719.

3. Al-Omari A, Abdelwahed HS, Alansari, MA. Critical care service in Saudi Arabia. Saudi Med J 2015; 36: 759-761.

4. Roch A, Wiramus S, Pauly V, Forel JM, Guervilly C, Gainnier $\mathrm{M}$, et al. Long-term outcome in medical patients aged 80 or over following admission to an intensive care unit. Crit Care 2011; 15: R36.

5. Dardaine V, Dequin PF, Ripault H, Constans T, Giniès G. Outcome of older patients requiring ventilatory support in intensive care: impact of nutritional status. J Am Geriatr Soc 2001; 49: 564-570.

6. Steenbergen S, Rijkenberg S, Adonis T, Kroeze G, van Stijn I, Endeman H. Long-term treated intensive care patients outcomes: the one-year mortality rate, quality of life, health care use and long-term complications as reported by general practitioners. BMC Anesthesiol 2015; 15; 142.

7. Bonfada D, dos Santos MM, Lima KC, Garcia-Altes A. Survival analysis of elderly patients in intensive care units. Rev Bras Geriatr Gerontol 2017; 20: 197-205.

8. Esteban A, Anzueto A, Frutos F, Alía I, Brochard L, Stewart TE, et al. Characteristics and outcomes in adult patients receiving mechanical ventilation: A 28-day international study. JAMA 2012; 287: 345-355.

9. Esteban A, Anzueto A, Frutos F, Alía I, Brochard L, Stewart TE, et al. Evolution of mortality over time in patients receiving mechanical ventilation. Am J Respir Crit Care Med 2013; 188: 220-230.

10. Peñuelas O, Frutos-Vivar F, Fernández C, Anzueto A, Epstein SK, Apezteguía C, et al. Characteristics and outcomes of ventilated patients according to time to liberation from mechanical ventilation. Am J Respir Crit Care Med 2011; 184: 430-437.

11. Alzeer A, BaHammam A, Masood M, Basha SJ, Alhamad E, Sohail S. Outcome of patients with severe asthma in the intensive care unit. Ann Saudi Med 2006; 26: 461-465.

12. Garout MA, Jokhdar HAA, Aljahdali IA, Zein AR, Goweda RA1, Hassan-Hussein A. Mortality rate of ICU patients with the Middle East Respiratory Syndrome - Coronavirus infection at King Fahad Hospital, Jeddah, Saudi Arabia. Cent Eur J Public Health 2018; 26: 87-91.

13. Al-Dorzi HM, Al Orainni H, Al Eid F, Tlayjeh H, Itani A, Al Hejazi A, et al. Characteristics and predictors of mortality of patients with hematologic malignancies requiring invasive mechanical ventilation. Ann Thorac Med 2017; 12: 259-265.

14. Haddad SH, YousefZM, Al-Azzam SS, AlDawood AS, Al-Zahrani AA, AlZamel HA, et al. Profile, outcome and predictors of mortality of abdomino-pelvic trauma patients in a tertiary intensive care unit in Saudi Arabia. Injury 20115; 46: 94-99.

15. Ministry of National Guard Health Affairs. Critical Care Service at King Abdulaziz Medical City, Riyadh. [Updated 2014. Accessed 4th February 2019]. Available from: http://ngha. med.sa/English/MedicalCities/AlRiyadh/NURSRV/ClinDept/ CriticalCS/Pages/default.aspx

16. Ministry of National Guard Health Affairs. King Abdullah Specialist Children's Hospital. [Updated 2015. Accessed 4th February 2019]. Available from: http://ngha.med.sa/English/ MedicalCities/kasch/Pages/operation.aspx

17. Mamary AJ1, Kondapaneni S, Vance GB, Gaughan JP, Martin UJ, Criner GJ. Survival in patients receiving prolonged ventilation: factors that influence outcome. Clin Med Insights Circ Respir Pulm Med 2011; 5; 17-26.

18. Stauffer JL, Fayter NA, Graves B, Cromb M, Lynch JC, Goebel P. Survival following mechanical ventilation for acute respiratory failure in adult men. Chest 1993; 104: 1222-1229.

19. Vasilyev S, Schaap RN, Mortensen JD. Hospital survival rates of patients with acute respiratory failure in modern respiratory intensive care units. An international, multicenter, prospective survey. Chest 1995; 107: 1083-1088.

20. Roupie E, Lepage E, Wysocki M, Fagon JY, Chastre J, Dreyfuss $\mathrm{D}$, et al. Prevalence, etiologies and outcome of the acute respiratory distress syndrome among hypoxemic ventilated patients. SRLF collaborative group on mechanical ventilation. Société de Réanimation de Langue Française. Intensive Care Med 1999; 25: 920-929.

21. Chiwhane A, Diwan S. Characteristics, outcome of patients on invasive mechanical ventilation: A single center experience from central India. Egypt J Crit Care Med 2016; 4: 113-118.

22. Ball L, Serpa Neto A, Pelosi P. Obesity and survival in critically ill patients with acute respiratory distress syndrome: a paradox within the paradox. Crit Care 2017; 21: 114.

23. Glass HC1, Costarino AT, Stayer SA, Brett CM, Cladis F, Davis PJ. Outcomes for extremely premature infants. Anesth Analg 2015; 120,: 1337-1351.

24. Malkar MB, Gardner WP, Mandy GT, Stenger MR, Nelin LD, Shepherd EG, et al. Respiratory severity score on day of life 30 is predictive of mortality and the length of mechanical ventilation in premature infants with protracted ventilation. Pediatr Pulmonol 2015; 50: 363-369.

25. Shalaby M, Khathlan N, Safder O, Fadel F, Farag YM, Singh A,. et al. Outcome of acute kidney injury in pediatric patients admitted to the intensive care unit. Clin Nephrol 2014; 82: 379-86. 